\title{
Indicadores de burnout em docentes de terapia ocupacional: um estudo piloto*
}

\section{Burnout indicators in teachers of occupational therapy: a pilot study}

\author{
Luciane Modesto Ruiz', Nilson Rogério da Silva²
}

RUIZ, L. M.; Silva N. R. da. Indicadores de burnout em docentes de terapia ocupacional: um estudo piloto. Rev. Ter. Ocup. Univ. São Paulo, v. 20, n. 2, p. 101-109, maio/ago. 2009.

RESUMO: Terapeutas ocupacionais enfrentam riscos a saúde que incluem exposição à angústia e ao comportamento difícil, tratamentos prolongados e intervenções com resultado incerto. No que se refere aos profissionais terapeutas ocupacionais que atuam na docência, pode-se dizer que existe uma duplicidade de fatores de risco, ou seja, daqueles decorrentes da atuação como profissionais da saúde e também de elementos presentes na prática docente. Profissionais da saúde e educação têm apresentado indicadores significativos de burnout, mas o tema tem sido pouco estudado a terapeutas ocupacionais. O presente estudo teve por objetivos identificar a presença de indicadores de burnout em terapeutas ocupacionais que atuam como docentes, bem como possíveis impactos sobre a saúde dos mesmos e na qualidade do serviço prestado ao aluno. Participaram da pesquisa 46 terapeutas ocupacionais que atuam como docentes em cursos de Terapia Ocupacional das instituições de ensino públicas e privadas do estado de São Paulo. Para a coleta de dados foi utilizado o protocolo MBI (Maslach Burnout Inventory). Os dados foram analisados por meio do pacote estatístico SPSS versão 13,0 e organizados em tabelas. Foram encontrados resultados significativos para a exaustão emocional (44,2\% da amostra apresentaram escore médio e alto para esta dimensão). Para a dimensão despersonalização, 18,3\% apresentaram escore médio e alto e somente $14,7 \%$ relataram a diminuição da realização pessoal. Os dados revelam a importância de medidas de prevenção e enfrentamento do burnout, visto que a dimensão da exaustão emocional é preditora para as demais.

DESCRITORES: Pessoal de saúde/educação. Docentes. Saúde ocupacional. Terapia ocupacional/ educação. Fatores de risco. Esgotamento profissional.

\footnotetext{
* Trabalho de Conclusão de Curso (TCC) apresentado ao Conselho do Curso de Graduação em Terapia Ocupacional, da Faculdade de Filosofia e Ciências - UNESP/Marília, como requisito parcial para obtenção do título de Bacharel em Terapia Ocupacional.

1. Terapeuta ocupacional graduada pela Universidade Estadual Paulista.

2. Professor Assistente Doutor, Docente do Curso de Terapia Ocupacional da Universidade Estadual Paulista - UNESP - Campus de Marília.

Endereço para correspondência: Rua Ana Rosa Zuicker Danunziatta, 2-27. CEP: 17030-310, Bauru, São Paulo, SP. E-mail: nilson@marilia.unesp.br
} 
RUIZ, L. M.; Silva N. R. da. Indicadores de burnout. Rev. Ter. Ocup. Univ. São Paulo, v. 20, n. 2, p. 101-109, maio/ago. 2009.

s doenças ocupacionais vêm aumentando no
Brasil e no mundo, e tem atingido os diferen-
tes segmentos profissionais. Trabalhadores de saúde como médicos, enfermeiros, terapeutas ocupacionais estão expostos aos diversos riscos e fatores predisponentes ao desequilíbrio biopsicossocial. Para Guimarães et al. (2005) os profissionais não deslocam a atenção necessária a estes aspectos e por vezes tais agravos se manifestam de forma silenciosa como problemas de saúde.

$\mathrm{Na}$ área da saúde, no Brasil, mudanças atingiram os serviços privados e estatais que passaram a adotar novas tecnologias e modelos de organização do trabalho. Neste processo, os profissionais de saúde foram submetidos à situações de instabilidade e precarização do contrato de trabalho, ritmos intensos, jornadas de trabalho prolongadas e redução da remuneração (SOBRINHO et al., 2006).

Tais fatores conduzem os profissionais, por exemplo, a conviverem com níveis elevados de stress e burnout em função da própria natureza de seu trabalho que envolve o lidar com situações de sofrimento e morte, podendo inclusive acarretar conseqüências na qualidade do atendimento aos beneficiários do seu trabalho.

O termo Burnout emergiu notoriamente nos anos 70 nos Estados Unidos por Freudenberger e no Brasil, nos anos 90, segundo revisão de Benevides-Pereira, 2002.

Benevides-Pereira (2002) definiu o Burnout como uma resposta a um estado prolongado de stress, ocorrendo pela sua cronificação, quando os métodos de enfrentamento falharam ou foram insuficientes.

Existem quatro concepções teóricas que buscam a etiologia da síndrome: a clínica, a sócio-psicológica, a organizacional e a sócio-histórica (MUROFUSE et al., 2005). A concepção sócio-psicológica tem sido mais adotada em grande parte devido à disseminação do Maslach Burnout Inventory (MBI), instrumento criado por Christina Maslach e Susan Jackson (1981) com traduções e validações em vários países, inclusive no Brasil. Para esta concepção o burnout é definido como uma síndrome composta de três dimensões: 1) Exaustão emocional (EE) - quando o individuo não conseguiu combater os agentes estressores, ocorrendo uma perda progressiva de energia, que levou a um esgotamento físico e mental; 2) despersonalização (DE) - o indivíduo não se importa mais em atingir seus objetivos e cumprir suas metas, relacionando-se friamente com as outras pessoas; 3) diminuição da realização pessoal (EP) - nesta fase, o sentimento de frustração, arrependimento e insatisfação fazem parte da vida do sujeito, julgando-se incapaz de cumprir com as demandas.
Para Benevides-Pereira (2002) entre os principais sintomas destacam-se os físicos que abrangem desde fadiga e cefaléias até transtornos cardio-respiratórios e osteomusculares, os psíquicos que variam desde a falta de concentração até a paranóia, os comportamentais que envolvem a negligência ou excesso de escrúpulos e até suicídio e ainda sintomas defensivos variam do isolamento até o absenteísmo e ironia.

A incidência de Burnout nos vários países ainda é incerta, TRIGO et al. (2007) sugerem que o número de indivíduos acometidos pode variar entre $4 \%$ a $85,7 \%$, dependendo da população estudada. O burnout é mais frequentemente observado em profissionais que trabalham na área assistencial, em contato direto e freqüente com a clientela na prestação de serviço, como profissionais da saúde, educação (CODO, 1999; REINHOLD, 2007). Entre estes profissionais pode-se incluir os terapeutas ocupacionais. Entre os fatores que favorecem a incidência do burnout nos profissionais da saúde, Maslach, Schaufeli \& Leitter (2001) apontam o contato com a morte e sofrimento, principalmente de crianças.

Os estudos sobre o Burnout com profissionais de saúde são mais freqüentes junto a médicos e enfermeiros (LAUTERT, 1997; CATALDO NETO et al., 1998; MIRANDA; QUEIROZ, 1991). Já as pesquisas com fisioterapeutas e terapeutas ocupacionais são mais escassas (BALOGUN et al., 2002), embora crescentes.

Maslach et al. (2001) e Kurowski (1999) indicaram a sobrecarga laboral como um intenso fator para o aparecimento da síndrome, já que a alta exigência das demandas no contexto do trabalho, acompanhada com o tempo limitado para a realização das tarefas gerariam uma grande exaustão emocional.

Terapeutas ocupacionais enfrentam riscos a saúde que incluem exposição à angústia e ao comportamento difícil, tratamentos prolongados e intervenções com resultado incerto. Além disso, questões como baixo status profissional, pessoais e questões da natureza da profissão são riscos adicionais (LLOYD; KING, 2001).

A incidência do burnout em terapeutas ocupacionais tem sido estudada em diversos países: Costa et al. (2003) em Madrid, na Espanha; Rogers e Dodson (1988), nos EUA; Rocha (2002) em Portugal; Quisling (1980) e Balogun et al. (2002) nos Estados Unidos, dentre outros. Consta na literatura que o pioneiro destas pesquisas foi Quisling (1980) que pesquisou 428 terapeutas ocupacionais no nordeste dos Estados Unidos. A pesquisa correlacionou o resultado ao Burnout, constatando baixa auto-estima, mudanças comportamentais e baixa 
RUIZ, L. M.; Silva N. R. da. Indicadores de burnout. Rev. Ter. Ocup. Univ. São Paulo, v. 20, n. 2, p. 101-109, maio/ago. 2009.

realização profissional (pensamentos de mudar de emprego).

Balogun et al. (2002) identificaram que dos 307 profissionais que atuavam em diferentes clínicas em Nova York, sendo 169 fisioterapeutas e 138 terapeutas ocupacionais, $58 \%$ encontravam-se com indicadores de exaustão emocional; $94 \%$ da amostra apresentaram sentimentos negativos em relação ao trabalho e aos pacientes e apenas $1 \%$ estavam satisfeitos com seus trabalhos. Os dados revelaram que o burnout é mais incidente nestes profissionais cuja média obtida para exaustão emocional no estudo foi de $28,9 \%$, enquanto que estudo prévio da população em geral era de $21 \%$. A mesma tendência foi encontrada quando comparado a outros profissionais cujas médias foram inferiores: médicos $(22,2 \%)$, educadores $(21,3 \%)$, e assistentes sociais $(21.4 \%)$. Este estudo também revelou uma despersonalização maior que as dos outros profissionais e uma significativa diferença de diminuição da realização pessoal. $\mathrm{O}$ autor sugere a necessidade de reorganização do ambiente, a fim de mitigar tensões que levam ao burnout. Frente aos estudos mencionados acima, pode dizer que os indicadores de burnout em profissionais terapeutas ocupacionais são significativos.

\section{Terapeutas ocupacionais docentes}

No que se refere aos profissionais terapeutas ocupacionais que atuam na docência, pode-se dizer que existe uma duplicidade de fatores de risco, ou seja, daqueles decorrentes da atuação como profissionais da saúde, conforme mencionada acima, mas também de elementos presentes na prática docente. Sabe-se que muitos docentes de terapia ocupacional além das disciplinas teóricas ministradas, desenvolvem atividades de estágio e, portanto estão intimamente ligados à prática, supervisionando e/ou atendendo os pacientes.

Carlotto (2002) aponta o aumento das responsabilidades e exigências sobre os educadores que se deparam com a necessidade de desempenhar varias funções ao mesmo tempo, como proporcionar apoio para o desenvolvimento pessoal do aluno; adotar um papel de julgamento; estimular sua autonomia, ao mesmo tempo, em que exige respeito às regras do grupo e da instituição e lidar com as políticas educacionais, políticas e econômicas.

Souza et al. (2003) consideram que no trabalho docente além da desvalorização, pode-se destacar: o pouco reconhecimento social, baixos salários, gestão autoritária, jornada extensa, formação deficitária, adoção de postu- ras inadequadas, excesso de ruído, classes com número excessivo de alunos e acúmulo de tarefas extra-classe. Acrescenta ainda a existência de infra-estrutura precária, carência de recursos materiais e humanos cujo resultado é a sobrecarga de trabalho.

Reinhold (2007) aponta que os professores estão submetidos a diversos fatores estressantes decorrentes do exercício profissional podendo desenvolver reações de stress em diferentes níveis, com manifestação de exaustão, depressão, raiva e sintomas psicossomáticos.

Mendes (2002) considera que a trilogia universidade, docência e exercício profissional na área da saúde demandam elevado gasto de energia para elaboração de estratégias de soluções dos problemas encontrados no cotidiano profissional. Para a autora tais condições constituem em provável agente estressor, podendo conduzir o profissional e o aluno à condição de esgotamento e alienação.

De acordo com Reis et al. (2006) as situações estressantes vivenciadas pelos professores repercutem na saúde física e mental dos mesmos, além de interferir em seu desempenho profissional. Meira (2007) afirma que uma vez presentes os sintomas de stress, haverá prejuízo intelectual, afetivo e social.

Existem pesquisas brasileiras a respeito do burnout junto a professores universitários (CARLOTTO, 2002; GARCIA; BENEVIDES-PEREIRA, 2003; MENDES, 2002), mas nota-se uma escassez de pesquisas com terapeutas ocupacionais que atuam como docentes.

Neste sentido, é possível concluir a partir do exposto que os docentes de terapia ocupacional enfrentam no seu cotidiano situação de constrangimento que podem oferecer risco à saúde, com destaque para as doenças emocionais como o burnout, objeto de estudo nesta pesquisa.

Tal estudo se justifica em função da escassez de estudo na literatura brasileira no sentido de avançar na produção de conhecimentos sobre as relações entre trabalho e bem-estar psíquico junto aos terapeutas ocupacionais docentes. A presença de constrangimentos pode constituir possíveis impactos para sua saúde e consequentemente para a qualidade dos serviços prestados, o que indica a importância desta temática ser estudada.

\section{OBJETIVOS}

Identificar a presença de indicadores de burnout em terapeutas ocupacionais que exercem a docência e possíveis impactos sobre a saúde dos mesmos e na qualidade do serviço prestado ao aluno. 
RUIZ, L. M.; Silva N. R. da. Indicadores de burnout. Rev. Ter. Ocup. Univ. São Paulo, v. 20, n. 2, p. 101-109, maio/ago. 2009.

\section{MÉTODO}

\section{Participantes}

A amostra foi composta por 46 terapeutas ocupacionais no exercício da docência, 12 de instituições de ensino públicas e 34 de privadas do Estado de São Paulo.

\section{Instrumento}

Para a coleta dos dados foi utilizado o protocolo Maslach Burnout Inventory -MBI, instrumento desenvolvido no início da década de 80 por Maslach e Jackson (1981). O MBI é uma escala composta de 22 itens com 7 possibilidades de respostas $(0=$ nunca; $6=$ todo dia $)$ para a intensidade de sintomas do burnout e contempla: 9 itens sobre exaustão emocional, 5 para despersonalização e 8 de diminuição da realização pessoal (POSIG; KICKUL, 2003). Contudo, nesta pesquisa foi utilizada a versão do MBI traduzida e validada para a realidade brasileira por Tamayo (1997), cuja pontuação utilizada pelo autor foi alterada para 5 , em relação à versão original que oferecia 7 possibilidades de respostas. Os escores, nesta versão, variam de 1 a 5 ( 1 = nunca, 2 = algumas vezes ao ano, 3 = algumas vezes ao mês, $4=$ algumas vezes por semana e $5=$ diariamente). A distribuição dos itens por escala é a seguinte: Exaustão Emocional: 1,2,3,6,8,13,14,16,20; Despersonalização: 5,10,11,15,22 e Diminuição da Realização Pessoal: 4,7,9,12,17,18,19,21.

\section{Procedimentos de coleta de dados}

O projeto foi aprovado pelo Comitê de Ética em Pesquisa da instituição.

- Levantamento dos docentes terapeutas ocupacionais das instituições de ensino públicas e privadas do Estado de São Paulo;

- Envio dos questionários do MBI pelo correio, juntamente com informações sobre os objetivos da pesquisa e solicitação de colaboração para realização do estudo. Também foi encaminhado o termo de consentimento livre e esclarecido. Cada participante recebeu um envelope selado para devolução do questionário e do termo de consentimento assinado.

- Foi estabelecido um contato prévio, via e-mail e/ou telefone, com coordenadores de instituição de ensino que ofereciam curso de graduação em terapia ocupacional no estado de São Paulo. De acordo com cada resposta houve um envio pelo correio da quantidade de questionários e termos de consentimentos para os terapeutas ocupacionais que atuavam como docentes nestas instituições. Foram enviados 84 questionários para instituições de ensino públicas e privadas, mas somente 48 retornaram, sendo que dois deles estavam incompletos e não foram incluídos na amostra. Por isso, foram utilizados nesta pesquisa 46 questionários. $\mathrm{O}$ índice de participação foi de aproximadamente $55 \%$.

\section{Procedimentos de tratamento e análise de dados}

Foi realizado Teste Qui-Quadrado com auxílio de um pacote estatístico (SPSS versão 13) para verificar as características de resposta do grupo. Os resultados foram organizados em tabelas.

\section{RESULTADOS E DISCUSSÃO}

Os resultados serão apresentados por meio das três escalas que compõe o burnout, ou seja, exaustão emocional, diminuição da realização pessoal e despersonalização.

Para análise dos resultados, por se tratar de uma distribuição de escores em uma escala do tipo Likert contendo 5 possibilidades de respostas, considerou-se os escores 1 ("nunca") e 2 ("raramente") como escore baixo, 3 ("algumas vezes") como médio e 4 ("frequentemente") e 5 ("sempre") como escore alto.

Na Tabela 1 é apresentada a distribuição da freqüência de ocorrência $(n=46)$ dos escores obtidos por item na escala de Exaustão Emocional.

Para todos os itens investigados os valores de $p$ apresentaram significância estatística indicando que existem padrões de respostas diferentes entre eles. Foram encontrados valores significativos para a exaustão emocional. Ressalta-se que considerando-se os escores totais, como se trata de 9 itens investigados e 46 participantes, os valores máximos perfazem 414 ocorrências.

Da análise geral, 231 ocorrências (81 no escore "nunca" e 150 no escore "raramente") apresentaram escore baixo, 140 ocorrências para "algumas vezes" que equivale ao escore médio e 43 ocorrências ( 37 no escore frequentemente e 06 no sempre) escore alto. Desta forma, considerando-se os somatórios dos escores médio e alto observa-se 183 ocorrências com indicadores para a exaustão emocional. Estes dados estão em concordância com os achados de Garcia e Benevides-Pereira (2003) que encontraram escores elevados para esgotamento emocional em professores universitários. 
RUIZ, L. M.; Silva N. R. da. Indicadores de burnout. Rev. Ter. Ocup. Univ. São Paulo, v. 20, n. 2, p. 101-109, maio/ago. 2009.

TABELA 1. Freqüência para os escores obtidos para a Exaustão Emocional (Teste Qui-Quadrado)

\begin{tabular}{|c|c|c|c|c|c|c|}
\hline Exaustão Emocional & $\begin{array}{c}1 \\
\text { Nunca }\end{array}$ & $\begin{array}{c}2 \\
\text { Raramente }\end{array}$ & $\begin{array}{c}3 \\
\text { Algumas- } \\
\text { vezes } \\
\end{array}$ & $\begin{array}{c}4 \\
\text { Freqüient. }\end{array}$ & $\begin{array}{c}5 \\
\text { Sempre }\end{array}$ & $\begin{array}{l}\text { Valor } \\
p\end{array}$ \\
\hline 1- Eu me sinto emocionalmente exausto pelo meu trabalho. & 4 & 15 & 22 & 5 & 0 & 0,000 \\
\hline 2- Eu me sinto esgotado ao final de um dia de trabalho. & 1 & 11 & 27 & 6 & 1 & 0,000 \\
\hline $\begin{array}{l}3 \text {-Eu me sinto cansado quando me levanto de manhã e tenho } \\
\text { que encarar outro dia de trabalho. }\end{array}$ & 9 & 20 & 13 & 4 & 0 & 0,008 \\
\hline $\begin{array}{l}6 \text { - Trabalhar com pessoas o dia inteiro é realmente um grande } \\
\text { esforço para mim. }\end{array}$ & 18 & 17 & 10 & 1 & 0 & 0,001 \\
\hline 8 - Eu me sinto esgotado com meu trabalho. & 5 & 18 & 17 & 6 & 0 & 0,006 \\
\hline 13 - Eu me sinto frustrado com meu trabalho. & 12 & 24 & 9 & 1 & 0 & 0,000 \\
\hline $\begin{array}{l}14 \text { - Eu sinto que estou trabalhando demais no meu empre- } \\
\text { go. }\end{array}$ & 4 & 6 & 21 & 10 & 5 & 0,000 \\
\hline $\begin{array}{l}16 \text { - Trabalhar diretamente com pessoas me deixa muito } \\
\text { estressado. }\end{array}$ & 14 & 20 & 10 & 2 & 0 & 0,002 \\
\hline $\begin{array}{l}20 \text { - No meu trabalho, eu me sinto como se estivesse no final } \\
\text { do meu limite. }\end{array}$ & 14 & 19 & 11 & 2 & 0 & 0,000 \\
\hline Total geral $=414$ & 81 & 150 & 140 & 37 & 6 & \\
\hline
\end{tabular}

Na descrição por item serão destacados aqueles com resultados mais representativos, considerando-se os 46 participantes. No item 1 "Eu me sinto emocionalmente exausto pelo meu trabalho", apresentou para o escore "algumas vezes" (22 ocorrências), "raramente" (15), "freqüentemente" (05), e "nunca" (04), revelando, na somatória, um total de 27 ocorrências para os escores médio e alto e 19 para o escore baixo. O item 2 "Eu me sinto esgotado ao final de um dia de trabalho" obteve no escore "algumas vezes" (27 ocorrências), "raramente" (11), "freqüentemente" (06), "sempre" (01), e "nunca" (01), resultando, na somatória, 34 ocorrências para os escores médio e alto e 12 para o escore baixo. Para o item 8 "Eu me sinto esgotado com meu trabalho" foi verificado no escore "raramente" (18 ocorrências), "algumas vezes" (17), "freqüentemente" (06) e "nunca" (05). Nesta questão, obteve-se um equilíbrio nas respostas, com 23 ocorrências para o escore baixo e 23 na somatória dos escores médio e alto. No item 14 "Eu sinto que estou trabalhando demais no meu emprego" o escore baixo obteve 10 ocorrências e a somatória dos escores médio e alto alcançaram o valor de 36 ocorrências.

De maneira geral, observa-se a presença significativa dos escores médios e alto para a exaustão emocional que juntos somam 183 ocorrências $(44,2 \%)$ do total de 414 ocorrências possíveis, o que revela de forma expressiva estes sentimentos entre os professores estudados. Tal condição indica sobrecarga de trabalho, fator predisponente ao burnout (BENEVIDES-PEREIRA, 2002; BURKE et al., 1996).

O fato de o docente apresentar exaustão emocional pode gerar conseqüências sérias tanto na sua saúde quanto no seu desenvolvimento profissional. Segundo Carloto (2002) a presença de indicadores de burnout implicar em prejuízos ao professor quanto ao planejamento de aula, alterações na motivação e na criatividade, diminuição da simpatia pelos alunos, diminuição das expectativas e distanciamento dos alunos.

Mendes (2002) em pesquisa com docentes universitários, inclusive terapeutas ocupacionais, encontrou um alto índice de exaustão emocional e um índice médio de despersonalização e diminuição da realização pessoal.

Para Benevides-Pereira (2002), o esgotamento emocional é uma das primeiras manifestações do burnout, logo, este estudo confirma o início desta dimensão nos terapeutas ocupacionais docentes estudados.

A dimensão da realização pessoal no trabalho também foi investigada e a distribuição da freqüência de ocorrência $(n=46)$ dos escores obtidos por item na escala é apresentada na Tabela 2. 
RUIZ, L. M.; Silva N. R. da. Indicadores de burnout. Rev. Ter. Ocup. Univ. São Paulo, v. 20, n. 2, p. 101-109, maio/ago. 2009.

TABELA 2. Freqüência para os escores obtidos para a Diminuição da Realização Pessoal (Teste Qui-Quadrado)

\begin{tabular}{|c|c|c|c|c|c|c|}
\hline $\begin{array}{c}\text { Diminuição da } \\
\text { Realização Pessoal }\end{array}$ & $\begin{array}{c}1 \\
\text { Nunca }\end{array}$ & $\begin{array}{c}2 \\
\text { Raramente }\end{array}$ & $\begin{array}{c}3 \\
\text { Alg. vezes }\end{array}$ & $\begin{array}{c}4 \\
\text { Freqüent. }\end{array}$ & $\begin{array}{c}5 \\
\text { Sempre } \\
\end{array}$ & Valor de $p$ \\
\hline $\begin{array}{l}4 \text { - Eu posso entender facilmente o que sentem os meus pacien- } \\
\text { tes acerca das coisas que acontecem no dia-a-dia. }\end{array}$ & 0 & 1 & 7 & 30 & 8 & 0,00 \\
\hline $\begin{array}{l}7 \text { - Eu trato de forma adequada os problemas de meus alu- } \\
\text { nos*. }\end{array}$ & 0 & 0 & 2 & 31 & 13 & 0,00 \\
\hline $\begin{array}{l}9 \text { - Eu sinto que estou influenciando positivamente a vida de } \\
\text { outras pessoas através do meu trabalho. }\end{array}$ & 0 & 3 & 5 & 27 & 11 & 0,00 \\
\hline 12 - Eu me sinto muito cheio de energia. & 1 & 4 & 12 & 26 & 3 & 0,00 \\
\hline $\begin{array}{l}17 \text { - Eu posso criar facilmente um ambiente tranqüilo com } \\
\text { os meus alunos. }\end{array}$ & 0 & 0 & 7 & 28 & 11 & 0,00 \\
\hline $\begin{array}{l}18 \text { - Eu me sinto estimulado depois de trabalhar lado a lado } \\
\text { com os meus alunos. }\end{array}$ & 0 & 0 & 3 & 29 & 14 & 0,00 \\
\hline $\begin{array}{l}19 \text { - Eu tenho realizado muitas coisas importantes neste } \\
\text { trabalho. }\end{array}$ & 0 & 1 & 4 & 34 & 7 & 0,00 \\
\hline $\begin{array}{l}21 \text { - No meu trabalho, eu lido com os problemas emocionais } \\
\text { com calma. }\end{array}$ & 0 & 0 & 4 & 33 & 9 & 0,00 \\
\hline Total Geral $=368$ & 1 & 9 & 44 & 238 & 76 & - \\
\hline
\end{tabular}

Nota-se que para todos os itens os valores de $p$ apresentaram significância estatística. Como se trata de uma escala negativa, quanto maiores os valores, melhores o indicadores de realização como o trabalho e vice-versa. Ressalta-se que considerando-se os escores totais, como se trata de 8 itens investigados e 46 participantes, os valores máximos perfazem 368 ocorrências.

Os dados revelam que a maioria dos docentes indicaram como resposta os escores "frequentemente" (238 ocorrências), seguido "sempre" (76), perfazendo um total de 314 ocorrências $(85,3 \%)$ para um alto indicador de realização pessoal com o trabalho. Para o escore médio "algumas vezes" foi encontrado 44 ocorrências, enquanto que para o escore baixo ("nunca" e "raramente") apenas 10 ocorrências, per-

Despersonalização (Teste Qui-Quadrado) fazendo um total de 54 ocorrências (14,7\%).

Apenas no item 12 "Eu me sinto muito cheio de energia", obteve-se 05 ocorrências para os escores baixo ("nunca" e "raramente") e 12 ocorrências para "algumas vezes". Assim obteve-se 17 ocorrências (de 46 possíveis) para o escores baixo e médio para esta dimensão e 29 para o escore alto. Este resultado pode ser considerado preocupante, na medida em que a falta de energia e disposição para o trabalho é um fator de risco para o desenvolvimento do burnout.

$\mathrm{Na}$ Tabela 3 é apresentada a distribuição da freqüência de ocorrência $(n=46)$ dos escores obtidos por item na escala de Despersonalização.

TABELA 3. Freqüência para os escores obtidos para a

\begin{tabular}{|c|c|c|c|c|c|c|}
\hline Despersonalização & $\begin{array}{c}1 \\
\text { Nunca }\end{array}$ & $\begin{array}{c}2 \\
\text { Raramente }\end{array}$ & $\begin{array}{c}3 \\
\text { Alg. vezes }\end{array}$ & $\begin{array}{c}4 \\
\text { Freqüent. }\end{array}$ & $\begin{array}{c}5 \\
\text { Sempre }\end{array}$ & $\begin{array}{l}\text { Valor } \\
\text { de } p\end{array}$ \\
\hline $\begin{array}{l}5 \text { - Eu sinto que trato alguns dos meus alunos como se eles } \\
\text { fossem objetos }\end{array}$ & 8 & 30 & 7 & 1 & 0 & 0,00 \\
\hline $\begin{array}{l}10 \text { - Eu sinto que me tornei mais insensível com as pessoas } \\
\text { desde que comecei este trabalho. }\end{array}$ & 13 & 31 & 2 & 0 & 0 & 0,00 \\
\hline $\begin{array}{l}11 \text { - Eu sinto que este trabalho está me endurecendo emo- } \\
\text { cionalmente. }\end{array}$ & 11 & 27 & 5 & 3 & 0 & 0,00 \\
\hline $\begin{array}{l}15 \text { - Eu não me importo realmente com o que acontece com } \\
\text { alguns dos meus alunos }\end{array}$ & 3 & 26 & 12 & 4 & 1 & 0,00 \\
\hline $\begin{array}{l}22 \text { - Eu sinto que os alunos me culpam por alguns de seus } \\
\text { problemas. }\end{array}$ & 11 & 28 & 7 & 0 & 0 & 0,00 \\
\hline Total geral $=\mathbf{2 3 0}$ & 46 & 142 & 33 & 8 & 1 & - \\
\hline
\end{tabular}


RUIZ, L. M.; Silva N. R. da. Indicadores de burnout. Rev. Ter. Ocup. Univ. São Paulo, v. 20, n. 2, p. 101-109, maio/ago. 2009.

$\mathrm{Na}$ escala que investiga a despersonalização, ressalta-se que considerando-se os escores totais, como se trata de 5 itens investigados e 46 participantes, os valores máximos perfazem 230 ocorrências. Os dados da Tabela 3 revelam que a maioria dos docentes indicou o escore baixo que obteve 188 ocorrências $(81,7 \%)$. Para o escore médio foi encontrado 33 ocorrências e apenas 09 para o escore alto, ou seja, apenas 42 ocorrências (18,3\%) apresentadas pela população estudada representam indicadores preocupantes nesta dimensão.

$\mathrm{Na}$ análise por item, apenas no item 15 "Eu não me importo realmente com o que acontece com alguns dos meus alunos", ainda que a maioria dos professores tenha indicado o escore baixo com 29 ocorrências (63\%), a somatória dos escores médio e alto obtiveram 17 respostas, o que equivale dizer que $37 \%$ dos docentes manifestaram algum grau de desinteresse pelas condições de ensino-aprendizagem dos alunos.

Ao se considerar as 3 escalas em conjunto, ressalta-se que a versão original do instrumento na sua validação considera a presença de burnout quando o indivíduo obtém escores altos para exaustão emocional e despersonalização e baixo para diminuição da realização pessoal. A partir deste critério, pode-se dizer que os docentes da amostra estudadas não apresentam burnout visto que os resultados indicam que apenas 43 ocorrências $(10,4 \%)$ para escores altos de exaustão emocional e 09 ocorrências (4\%) apresentaram escores altos para despersonalização.

Segundo Maslach e Leitter (1997), uma pessoa não começa um trabalho apresentando burnout, pois geralmente este início é marcado de satisfação e engajamento. Gradualmente, estes sentimentos vão sendo substituídos por comportamentos e atitudes negativos. Com isso, como primeiro elemento do burnout, aparece a exaustão emocional. Como conseqüência da falta de ânimo e energia, o indivíduo desenvolve um afastamento psíquico e emocional da clientela e de suas relações, podendo atingir inclusive suas relações sociais. Trata-se mais especificamente do elemento despersonalização.

No entanto, a situação se agrava quando somada ao aspecto exaustão emocional, a despersonalização leva ao comprometimento do desempenho e sensação de incompetência estabelecendo-se assim, a redução do sentimento de realização profissional ou ainda baixo envolvimento pessoal no trabalho.

\section{CONSIDERAÇÕES FINAIS}

Esta pesquisa revelou um escore para exaustão emocional considerável, enquanto as dimensões despersonalização e diminuição da realização pessoal não apresentaram resultados significativos.

Contudo, há necessidade de ressaltar que o burnout tem caráter insidioso, cumulativo e com tendência à severidade. Desta forma, a incidência de escores médios para a exaustão emocional, visto que se trata de uma dimensão que pode ser considerada preditora para a diminuição da realização pessoal e despersonalização, e não pode ser desconsidera enquanto processo de adoecimento.

As conseqüências do burnout em terapeutas ocupacionais docentes se manifestam no campo pessoalprofissional, trazendo repercussões sobre a organização escolar e/ou no âmbito da clínica e na relação com os alunos e/ou clientes, por isso reforçam a importância da sua prevenção.

Quanto ao diagnóstico, burnout e suas dimensões são reconhecidas como variáveis contínuas, e seu desenvolvimento dependem de fatores individuais e organizacionais, podendo se agravar ao longo dos anos.

No entanto, na medida em que entendemos melhor este fenômeno psicossocial como processo, identificando suas etapas e dimensões, pode-se prevenir minimizar ou eliminar o desenvolvimento do burnout. Desta forma, torna-se possível auxiliar o professor para que este concretize seu projeto de vida pessoal e profissional, melhorando sua qualidade de vida e de todos os envolvidos no sistema educacional.

Ressalta-se a importância de um estudo mais amplo que aborde uma amostra maior de docentes de terapia ocupacional, que considere variáveis como regime de trabalho, possíveis diferenças entre público e privado, tempo de formação e experiência, para que os resultados possam ser generalizados.

Contudo, espera-se que os dados apresentados possam fomentar novas pesquisas e questionamentos sobre a prática docente em terapia ocupacional e, sobretudo sobre a importância de prevenção de doenças ocupacionais, como o burnout, objeto da presente pesquisa.

Observa-se uma escassez de estudos sobre indicadores de burnout em terapeutas ocupacionais em nosso país e mesmo na literatura estrangeira, o que dificultou a comparação dos resultados obtidos neste estudo, revelando a necessidade de investimento em pesquisa nesta temática. 
RUIZ, L. M.; Silva N. R. da. Indicadores de burnout. Rev. Ter. Ocup. Univ. São Paulo, v. 20, n. 2, p. 101-109, maio/ago. 2009.

RUIZ, L. M.; Silva N. R. da. Burnout indicators in teachers of occupational therapy: a pilot study. Rev. Ter. Ocup. Univ. São Paulo, v. 20, n. 2, p. 101-109, maio/ago. 2009.

\begin{abstract}
Occupational therapists face risks to health that include exhibition to the anguish and difficult behaviour, long-term treatment and intervention with uncertain result. In regard to practice, occupational therapists who are also teachers, face duplicity of risk factors, that is, the ones related to the intervention as health professionals and those caused by educational practice. Health and education professionals have been presenting significant indicators of burnout, but the theme has been less studied in occupational therapists. The present study aimed to identify the presence of burnout indicators in occupational therapists who are also teachers, possible impacts on their health and in the quality of service provided for the students. Forty-six occupational therapists who are teachers in Occupational Therapy programs of public and private schools of the state of São Paulo took part in the research. For data collection the MBI (Maslach Burnout Inventory) protocol was used. Data were analysed by means of the statistical package SPSS version 13,0 and then organized in tables. The data were analyzed using the statistical package SPSS version 13,0 and organized into tables. The results were significant for the emotional exhaustion $(44.2 \%$ of the sample showed average medium and high scores). In relation to depersonalization, $18,3 \%$ showed a medium and high average score and only $14,7 \%$ reported a decline in personal accomplishment fulfillment. Data revealed the importance of prevention measures and coping in regard to burnout, because the dimension of the emotional exhaustion is predictive for the others.
\end{abstract}

KEY WORDS: Health personnel/education. Faculty. Occupational health. Occupational therapy/ education. Risk factors. Burnout/professional.

\title{
REFERÊNCIAS
}

BALOGUN, J. A.; TITILOYE, V.; BALOGUN, A.; OYEYEMI, A.; KATZ, J. Prevalence and determinants of burnout among physical and occupational therapists. J. Allied Health, New York, 2002.

BENEVIDES-PEREIRA, A. M. T. MBI - Maslash Burnout Inventory e suas adaptações para o Brasil. In: SOCIEDADE BRASILEIRA DE PSICOLOGIA(Org.) Resumos de Comunicação Científica. XXXII Reunião Anual de Psicologia, 2001. p.8485.

BENEVIDES-PEREIRA, A. M. T. Burnout: quando o trabalho ameaça o bem-estar do trabalhador. São Paulo: Casa do Psicólogo, 2002.

BURKE, R. J.; GREENGLASS, E. R.; SCHWARZER, R. Predicting teacher burnout over time: effects of work stress, social support and self-doubts on Burnout and its consequences. Anxiety, Stress Coping, v. 9, n. 3, p. 261-275, 1996.

CARLOTTO, M. S. A síndrome de Burnout e o trabalho docente. Psicol. Estud. Maringá, v. 7, n. 1, jan./jun. 2002.

CATALDO NETO, A.; CAVALET, D.; BRUXEL, D.; KAPPES, D.; SILVA, D. O estudante de medicina e o estresse acadêmico. Rev. Med. PUC-RS, v.8, p. 6-12, 1998.

CODO. W. (org.) Educação: carinho e trabalho. $4^{\mathrm{a}}$ ed. Petrópolis:
Vozes, 1999.

COSTA, N. A.; CUADros, J. A.; GUTIERREZ, J. L. G.; RODRÍGUEZ, R. M.; PUENTE, C. P.; RECIO, L. A.; CERRO, P. B. Burnout en terapia ocupacional: un análisis focalizado sobre el nivel de consecuencias individuales y organizacionales. Rev. Psicol. Trabajo Organizaciones, Madrid, Espanha, v. 19, n. 1, p. 59-73, 2003.

GARCIA, L. P.; BENEVIDES-PEREIRA, A. M. T. Investigando o Burnout em Professores Universitários. Maringá, Rev Eletrônica InterAção Psy. v. 1, n 1, p. 76-89, 2003.

GUIMARÃES, R. M.; MAURO, M. Y. C.; MENDES, R.; MELO, A. O.; COSTA, T. F. Fatores ergonômicos de risco e de proteção contra acidentes de trabalho: um estudo caso-controle. Rev. Bras. Epidemiol. v.8, n.3, pp. 282-294, 2005.

KUROWSKI, C. M. El Burnout em penitenciaria. Síndrome de Burnout em el sistema penitenciário brasileño - Paraná. Tese (Doutorado). Universidad Autónoma de Madrid, Madrid Espanha, 1999.

LAUTERT, L. O desgaste profissional: estudo empírico com enfermeiras que trabalham em hospitais. Rev. Gaucha Enferm. v. 18, p. 133-144, 1997.

LLOYD, C.; KING, R. Work related and occupational therapy. 
Occup. Ther. Int., Queensland, Austrália, 2001.

MASLACH, C.; JACKSON, S. E. Maslach Bournout Inventory. Human services survey. Palo Alto, CA: Consulting Psychologics Press, 1981.

MASLACH, C.; LEITTER, M. P. Trabalho: fonte de prazer ou desgaste. Campinas: Papirus, 1997.

MASLACH, C; SCHAUFELI, W. B.; LEITTER, M. P. Job Burnout. Annu. Rev. Psychol., n. 52, p. 397-422, 2001.

MEIRA, A. M. A. S. Implicações do stress de professores e alunos no processo de alfabetização. In: LIPP, M. E. N. O stress do professor. 5. ed. São Paulo: Papirus, 2007, p.29-39

MENDES, F. M. P. Incidência de Burnout em professores Universitários. Curitiba, 2002. Dissertação (Mestrado em Engenharia de Produção) - Programa de Pós-Graduação em Engenharia de Produção, 2002.

MIRANDA, P. S. C.; QUEIRÓZ, E. A. Pensamento suicida e tentativa de suicídio entre estudantes de medicina. Rev. ABP-APAL, v.13, p.157-160, 1991.

MUROFUSE, N.T.; ABRANCHES, S.S.; NAPOLEÃO, A.A. Reflexões sobre estresse e Burnout e a relação com a enfermagem. Rev. Latinoam. Enferm., v.13, p. 255-261, 2005.

POSIG, M.; KICKUL, J. Extending our understanding of Burnout: Test of na integrated model in nonservice occupations. J. Occup. Health Psychol., v.8, n.1, p. 3-19, 2003.

QUISLING, C. Phenomenon of Burnout in occupational therapy. MA Thesis. Boston University. Boston, 1980.
REINHOLD, H. H. O Burnout. In: LIPP, M. E. N. O stress do professor. 5. ed. São Paulo: Papirus, 2007, p.63-80.

REIS, E. J. F. B.; ARAÚJO, T. M.; CARVALHO, F. M.; BARBALHO, L.; SILVA, M. O. Docência e exaustão emocional. Educação Sociedade, Campinas, v. 27, n. 94, p. 229-253, 2006.

ROCHA, N. Burnout nos profissionais de terapêutica ocupacional. Trabalho de conclusão de curso. Escola Superior de Tecnologia de Saúde do Porto. Portugal, 2002.

ROGERS, J. C.; DODSON, S. C. Burnout in occupational therapists. Am. J. Occup. Ther., Pennsylvania, n. 42, p. 787-792, 1988.

SOBRINHO, C. L. N.; CARVALHO, F. M.; BONFIM, T. A. S.; CIRINO, C. A. S.; FERREIRA, I. S. Condições de trabalho e saúde mental dos médicos de Salvador, Bahia, Brasil. Cad. Saude Publica, Rio de Janeiro, v. 22, n. 1, 2006.

SOUZA, K. R.; SANTOS, M. B. M.; PINA, J. A.; MARIA, A. B. V.; CARMO, M. A. T.; JENSEN. M. Trajetória do Sindicato Estadual dos Profissionais da Educação do Rio de Janeiro (Sepe-RJ) na luta pela saúde no trabalho. Cien. Saude Coletiva, v. 8, n. 2, p. 157-168, 2003.

TAMAYO, M.R. Relação entre a síndrome de Burnout e os valores organizacionais no pessoal de enfermagem de dois hospitais públicos. Dissertação de Mestrado, Instituto de Psicologia, Universidade de Brasília, 1997.

TRIGO, T. R.; TENG, C. T.; HALLAK, J. E. C. Síndrome de burnout ou estafa profissional e os transtornos psiquiátricos. São Paulo: Rev. Psiq. Clín.. v 34, n. 5, p. 223-233, 2007. 